function was of lesser importance. It was much more important that the patient had his legs in the correct position. With regard to the bladder, he would have a permanent catheter.

Hingorani, $K$. (England), asked the speaker (I) how far could he successfully localise the effect of phenol block to a certain nerve root without the danger of the substance spreading to involve other nerve roots and (2) what was the duration of the effect of phenol block in terms of time with regard to spasticity.

Sotelano, F. H., replied (I) that the patient was rotated $45^{\circ}$ and then the injection was done. It was not known exactly in what group they would put the phenol, but he did not care very much because they had a spastic patient with a spastic bladder and must relieve this; whether $\mathrm{L}_{3}, 4,5$, it did not matter. (2) The duration of the effect was one year.

\title{
PHLEBO-THROMBOSIS AND PULMONARY EMBOLISM IN PARAPLEGIA
}

\author{
By J. J. Walsh, M.D. and C. TRIBe, D.M., B.Ch. \\ National Spinal Injuries Centre, Stoke Mandeville Hospital, Aylesbury, England
}

Clinical Aspects. The material for this paper consists of 500 traumatic paraplegics and tetraplegics admitted to the National Spinal Injuries Centre within fourteen days of injury.

An attempt was made to relate the incidence of phlebo-thrombosis and pulmonary embolism to a number of factors including age, sex, level and type of lesion, associated injuries, early operation and blood transfusion, and to assess the value of daily passive movements in the lower limbs in preventing phlebo-thrombosis.

In addition, an analysis was made derived from post-mortem material from this series.

The overall incidence of phlebo-thrombosis and/or pulmonary embolism was found to be 66 cases ( 13.2 per cent.), of which I5 ( 3 per cent.) were fatal.

The striking relationships established were ( $\mathrm{I})$ a higher incidence in complete lesions ( 16.5 per cent.) as compared with incomplete lesions (9 per cent.); (2) a high incidence in complete thoracic lesions (I9. I per cent.); and (3) a very high incidence in one particular year (25.3 per cent.). The value of twice-daily passive movement of the lower limbs for Io minutes during the first six weeks after injury was not apparent. The question of prophylactic anticoagulant therapy is discussed.

Pathological Aspect. Fifteen out of 3I cases of traumatic paraplegia who died from causes related to the paraplegia (group I) showed massive pulmonary embolism as the primary cause of death. Fatal pulmonary embolism occurred at any time from 4 to 85 days following the onset of paraplegia. There appeared to be a relationship between the presence of urinary infection and pelvic vein thrombosis.

\section{Discussion}

Dollfus, $P$., asked two questions: (I) Had they given up completely at Stoke Mandeville putting blood transfusions in the lower limbs? (2) Had patients who were treated 
systematically by anticoagulants from the time they came into hospital developed gastric bleedings caused by anticoagulants?

Walsh, $\mathcal{F} . \mathcal{F}$., replied that blood transfusions to the lower limbs were still given in later stages. It was much more convenient for the patient. They had given up doing so in new lesions.

Meinecke, F. W. (Germany), answering Dr. Dollfus's second question, said that three years ago, after the paper of Dr. Tribe, there had been nearly the same discussion about this important point of embolism and thrombosis. At that time he had said that he had treated nearly all patients in his hospital who would stay longer than six weeks in bed routinely on anticoagulants. But it was found that thrombosis and embolism could not be avoided and some paraplegics died from embolism within the first few weeks, and, therefore, this was given up. Since I 962 , this had not been done routinely, but he had the impression that certainly not more but less embolism and thrombosis occurred than previously. He thought it was not necessary to do it routinely. If one used anticoagulant therapy routinely one needed two things: (I) an excellent laboratory that did nothing else but survey this therapy and (2) a minimum of three months, as otherwise the therapy would be too dangerous, and if one did not survey this therapy very carefully one would see that embolism and thrombosis would increase and the therapy would be very dangerous. He had not seen bleedings of gastric ulcers and bleedings of kidneys. One had to examine the urine for blood cells, but he had not seen very heavy bleeding in connection with anticoagulant therapy.

Rossier, $A$. (Switzerland), said that his figures went in exactly the same direction as those of Dr. Tribe. They had had in Zurich exactly 32 acute cases and seven deaths, five of which were due to pulmonary embolism which were provided by the autopsy-i.e. I6 per cent. of mortality because of embolism in acute cases. They could not find a single embolism in chronic paraplegia. On account of these figures, it was decided to try prophylactic anticoagulant therapy. He agreed with Dr. Meinecke that if those conditions which he mentioned were not fulfilled it was perhaps better to withhold such therapy. He would like to give the latest figures of his Unit in Geneva, which were small but rather conclusive: six acute cases with about the same type of complication-i.e. fracture of ribs, haemopneumothorax, tracheostomy. Three of them were put on anticoagulant therapy. The three who were put under anticoagulant therapy as soon as the bleeding danger was out of the question had no visible thrombosis or pulmonary embolism. On the other hand, the three others did-two had deep venous thrombosis, one died from another reason but had multiple pulmonary embolism at necropsy.

Harris, $P$., said this was a common and very important condition and he wondered whether Dr. Walsh could give some pointers regarding early diagnosis. Had Dr. Tribe come across pulmonary thrombosis in any of his patients? This might be important in those especially with chest injuries. Which leg veins were mainly affected? He wondered about the retention of the patient in supine position regarding venous stasis and felt the prone position for a while was of value. He further asked Dr. Walsh about prevention of those terrible complications without anticoagulants, and thought of breathing exercises especially for those with chest trouble which increased the venous return, and a technique which was simple and worth while to elevate the patient's legs or the whole patient in some way regularly for part of the 24 hours at intervals. He felt that even $15^{\circ}$ elevation of the legs could make a tremendous difference to the venous return and help to prevent this condition.

Walsh, F. F., in reply said that oedema of the legs was the first symptom and must be differentiated from postural oedema. It was very common to find a swollen leg after a patient had been lying on his side. As a practical test, the patient was not put on that particular side for 24 hours. If the oedema had disappeared one could fairly be sure that it was not a deep vein thrombosis. If one had a case of thrombosis one had some pyrexia, and a combination of a swollen leg with a low-grade temperature was fairly diagnostic of it. 
With regard to prevention, there might be something in this question of tilting. Breathing exercises all the patients had pretty well every day in the first week or two and the cervicals went on for a much longer period. All cervical patients were tilted head down regularly within the 24 hours for chest physiotherapy. It might be significant that the incidence in his own figures amongst the cervical lesions was relatively low-about ro per cent as compared with 16 per cent. in the other cases. Lower lesions were not tilted as a routine. With regard to lying prone (and he presumed Mr. Harris was thinking of pressure on the calf veins), he had not done this. There were other contra-indications to putting them prone in the great majority of cases. Chest physiotherapy and tilting were the two precautions one should take. The other thing was to avoid transfusing in the lower limb; one must accept that this was probably dangerous. Giving anticoagulants did not appear to have any prophylactic value, from what Dr. Rossier and Dr. Meinecke had said.

Tribe, C., said he had not seen any cases of pulmonary thrombosis-otherwise in every case he had been able to demonstrate deep vein thrombosis. There had been no long-standing thrombosis in any of the pulmonary vessels. As to which leg veins were affected, he thought in this case one should accept Dr. Walsh's figures rather than his own. As a pathologist, one tended initially to be satisfied with finding a thrombosis, but he had now started to try to dissect out the whole of the venous system of the legs and pelvis. He would like to make a general comment, especially in response to Dr. Rossier's figures. He would entirely agree and hoped that Dr. Rossier would continue his survey, as he thought it important that at least one centre should be able to produce accurate statistical figures from enough number of cases who had been treated with anticoagulants from a very early state as opposed to a control group. There was doubt reading the literature, especially from the Accident Hospital, Birmingham, where they had great success from early anticoagulation in the prevention of pulmonary embolism.

$\operatorname{Hardy}, A$. G., wondered how many of the pulmonary emboli which had been fatal arose in circumstances which had not been identified previously. His experience had been that the fatal cases had arisen in a certain number of cases in totally unexpected circumstances; in other words, no fat leg.

Walsh, F. F., agreed. If one got a swollen leg one could begin to feel fairly happy that one was unlikely to get a large pulmonary embolus. The majority of his fatal pulmonary emboli had occurred without obvious signs of leg oedema or leg swelling.

Cheshire, D.F. E., said he would like to try to introduce some indirect evidence which might confirm Dr. Walsh's contention concerning the relationship of physiotherapy to deep vein thrombosis. Dr. Walsh in his series had described I2 deaths of pulmonary embolism in 428 acute lesions. As an ex-pupil of Dr. Guttmann's, the patients being managed in his unit in Australia and those being managed at Stoke Mandeville were very comparable in all respects except one. As far as surgery, nursing regime, turning regime and physiotherapy regime were concerned they were as comparable as two groups of patients could be. But 85 per cent. of his patients were admitted within 24 hours. Dr. Guttmann's were, broadly speaking, extending that little bit longer. His series was now 360 acute cases with two fatal pulmonary emboli, and one of those was admitted on the tenth day from another hospital and died on the eleventh. This could, he thought, be confirmatory evidence.

Benassy, $\mathfrak{F}$., emphasised the danger of the second transportation of those patients. At first they went to a general hospital and afterwards to a Centre. They should not be transported without previous preventative therapy by anticoagulants, and he too had had several deaths on the very evening of the day immediately after admission to the Centre two or three weeks after the accident.

Cibeira, $\mathcal{F}$., said that in his Centre they received the patients after one and a half to two months all with laminectomy, and out of 200 patients they had seen only one patient with embolism. Two things never occurred in his Centre-embolism and ectopic calcification. The only connection he could say was that they had a very high protein type of regime. 
Kerr, W. G., said it was quite obviously a very confusing subject. Dr. Cheshire gave remarkable figures and suggested that a factor might be early admission. His Centre in Edinburgh was very small and unfortunately could not admit the patients on the day of injury except very rarely. He had had no pulmonary embolisms amongst the patients who had been admitted and only one or two phlebothromboses. These were late admissions within one or two months. On the other hand, he knew that Mr. Harris, who had been receiving cases directly after injury in the Neurosurgical Unit of the Royal Infirmary, had an incidence of embolism.

Walsh, F. F., thought that the points raised by both Mr. Kerr and Dr. Cibeira about the very low incidence in their Units were answered by what they had said themselvesthey only admitted cases fairly late. The ones that had had fatal emboli they did not see.

Guttmann, L., said that what Mr. Kerrand Dr. Walsh had just said could beconfirmed also by Dr. Bors and Dr. Talbot of the U.S.A., who also got their cases very late and their incidence of thrombosis was, of course, small. Dr. Cheshire had brought up a very important point - the second transfer, say within 8 and I4 days, might be a dangerous period for this, and that was one of the reasons why he had advocated the transfer of patients to a paraplegic unit immediately after the first traumatic shock treatment had been carried out. If that were done religiously he felt one would be in a position within perhaps three or four years to make a clear statement on this important point.

With regard to anticoagulants, what Meinecke had said was a very important point, which one should consider. At Stoke Mandeville, they had had two or three cases who had had some more serious bleedings. Perhaps it would be a good thing if one were to examine the urine systematically for red cells when one anticoagulated. That might be an important point. Someone reported a few years ago about a case who had had a subdural bleeding during the period of anticoagulants.

Harris, $P$., said that these were three patients who had come to his Unit without previously any neurological involvement but had been on anticoagulants for other conditions, cardiac in particular, and during this time they had developed a spontaneous spinal epidural haemorrhage with a rapid progressive paraparesis.

Guttmann, L., said that another point he considered as most important was not to indulge in hasty operation immediately after injury. There was no doubt whatsoever that immediate operation was an additional danger in producing thrombosis. This was another reason why he was against hasty operations regardless of whether they were laminectomy or open reduction. All these things one had to consider very carefully, in view of this very serious and fatal incidence.

Meidema, $\mathcal{F}$. (Holland), commented that in 50 cases they did not have one death from pulmonary embolism but had mostly second transfer patients coming one to four months after injury. One would probably improve in death cases if one improved in getting the patients earlier.

Harris, P., thought one had to be careful about facts: (I) Dr. Guttmann mentioned the dangers of operation. He did not know how many of the patients in Dr. Walsh's series had operations and he thought one would need to know this in this paper. (2) He also would like to know, when this paper was published, at what stage following injury were they admitted primarily to Stoke Mandeville or from elsewhere, to try and link up with Dr. Cheshire's point.

Cheshire, D. F. E., said he would like to take this a stage further and suggest that Dr. Walsh might even consider trying, as far as was possible, to make an opinion from the case records of the adequacy or inadequacy of the physiotherapy received in hospital prior to coming to Stoke Mandeville.

Tribe, $C$., said it was well known that there was risk in anticoagulating patients and one had to assess the risks between anticoagulation: if one had an overall incidence, as they had, of 3 per cent. fatality one had to assess very carefully whether putting these patients on anticoagulants was justified. Therefore, one only hoped that Dr. Rossier would continue his series. If he had to make up his mind to advise in the Centre at Stoke 
Mandeville, he would find it very difficult for a reason he had not mentioned before that in many of these recent post-mortems he had performed on acute paraplegics there had been a high incidence of what was called stress ulcers of the gastro-intestinal tract; in fact, there was one mortality purely due to this complication and there had been two other cases in which there had been very severe bleeding and in many of them he had found small gastric erosions, acute necrotic erosions which had no specific pathology; they were very intriguing lesions but he thought this must be a common lesion in any acute trauma, not only paraplegics, and this should well be borne in mind.

\section{TEN YEARS’ REHABILITATING PARAPLEGICS}

By M. Blanco Argüelles, M.D.,J. Martinez Garcia, M.D., and E. Robles Gómez, M.D. Clínica National del Trabajo and Instituto y Escuela National de Medicina del Trabajo, Madrid, Spain

(Paper presented by Dr. MaRTINEZ Garcia)

THIS paper presents the results and conclusions obtained with the treatment of a series of patients treated in the Institutions mentioned above.

Our series comprises 224 cases, I86 of which were treated in the Clínica National del Trabajo and the other 38 in the Instituto de Medicina y Seguridad del Trabajo. The I 86 patients cared for at the Clínica National del Trabajo, correspond to the 25 beds available at this Centre for paraplegics who were treated from October 1955 to May I 965 . The 38 patients treated at the Instituto National de Medicina y Seguridad del Trabajo comprise a period from October 1963 to May I965 and who occupied the beds available at this Centre for this type of disabled.

Slides are shown which present the clinical types, complications, ulcers, contractures, average time of treatment and results obtained.

With the exception of eight cases due to various causes, all the patients were injured during accidents at work throughout the national territory. The patients' age was between 13 and 63 years, the higher percentage (4I.98 per cent.) being between 30 and 40 years of age.

It is to be noted that there has hardly ever been a coincidence between the level of the bone injury and the level of cord injury. The most affected segment has been LI with 39 cases (54.16 per cent.).

Within the forms of paraplegia, the flaccid type was the most predominant, reaching 54.0I per cent. with I2I cases. There has also been an important number of paraparesis.

Almost 100 per cent. of the patients who came to us one month after injury showed ulcers in various parts of the body and in various number. The same applied to contractures and deformities. In the last three years, however, a definite reduction in the number of these complications has been noticed; this is probably due to the publicity campaigns by the Clínica National del Trabajo, as well as by other Centres, on the correct way of treating these patients immediately after their accidents.

We would like to point out the good results obtained by us with the intra- 